\title{
Prevalence of obesity among the school going adolescents in urban Bangalore
}

\author{
Niranjan $\mathbf{H S}^{1^{*}}$, Nijaguna $\mathbf{N}^{2}$, Kamath $\mathbf{G}^{3}$ \\ ${ }^{1}$ Dr. Niranjan H S, Associate professor of Pediatrics, Indira Gandhi Institute of Children, Bangalore, ${ }^{2}$ Dr. Nijaguna N , \\ Associate professor of Pediatrics, Indira Gandhi Institute of Children, Bangalore, ${ }^{3}$ Dr Ganesh Kamath, Resident, Indira \\ Gandhi Institute of Children, Bangalore, Karntaka,India
}

Address for correspondence: Dr. Niranjan H S, Associate professor of Pediatrics, Indira Gandhi Institute of Children, South hospital complex, Bangalore, Email: drniranjan_hs@yahoo.com

\begin{abstract}
Background: Obesity, one of the most widespread and major problems affecting children and adolescents is of global nutritional concern. We conducted this study to estimate the prevalence of obesity among urban Bangalore school going adolescents. Material and Methods: School based cross-sectional study was conducted in schools in Bangalore during December 2012 to November 2013. The students were given a pre-designed structured questionnaire which consisted of questions to be answered by the student, with the help of his/her parents at home. Anthropometric measurements were taken to determine the prevalence of obesity. Results: This was an observational study consisting of 748 children is undertaken to study the prevalence of obesity. Prevalence of obesity in adolescents was found to be $5.9 \%$ in the present study. Prevalence of obesity was highest among in 15 year old adolescents $(9.3 \%)$ as compared to the overall prevalence of $5.9 \%(\mathrm{p}=0.039)$. The prevalence of obesity among adolescents had a birth weight $>3.5 \mathrm{~kg}$ was $10.7 \%(\mathrm{p}=0.069)$. Among obese adolescents, $79.5 \%$ had mixed diet pattern. Among adolescents with family history of obesity, $22.9 \%$ were obese as compared to $4.1 \%$ prevalence of obesity among adolescents without family history of obesity. Majority of obese adolescents belonged to upper middle class socioeconomic status $(9.6 \%)(p=0.028)$. Conclusion: There is a significant prevalence of obesity among adolescents of urban Bangalore. Mixed diet, upper middle class SES and family history of obesity have a strong correlation with the prevalence of obesity in adolescents.
\end{abstract}

Key word: Obesity, Adolescents, Urban

\section{Introduction}

Obesity, one of the most widespread and major problems affecting children and adolescents is of global nutritional concern. An increased prevalence is found in many countries where the major nutritional disorder previously was malnutrition [1].

Increase in prevalence of childhood obesity is associated with potential medical complications of obesity noted in adolescence and especially in adulthood, like hypertension, coronary artery disease, cerebrovascular accidents, diabetes mellitus type 2, dyslipidemia, gall stones, premature joint destruction and many others $[2,3]$.

In last two decades, the prevalence of obesity has doubled in children and tripled in adolescents in United

Manuscript received: $4^{\text {th }}$ Nov 2015

Reviewed: $15^{\text {th }}$ Nov 2015

Author Corrected: $27^{\text {th }}$ Nov 2015

Accepted for Publication: $14^{\text {th }}$ Dec 2015
States of America. The increase in childhood and adolescent obesity has resulted in increase in over weight and obesity in adults. [4]. This has a profound public health consequence as $80 \%$ of overweight children become overweight adults.

In addition, obesity has a negative impact on selfesteem of children and adolescents, which may have significant implications for long-term happiness and success in life. Finally, directed sessions that emphasize healthy eating and exercise habits for children and their families may have lasting effects on life style of these children [5].

Evaluation of obesity in childhood is important for several reasons. Firstly, it offers the best hope for preventing disease progression with its associated morbidities in adulthood. Secondly, though genetic and 
hormonal causes of obesity are rare, they do warrant consideration in obese children.

There is not enough data on the prevalence of obesity in adolescents in urban Bangalore. Hence, the present study aims to fulfill this urgent requirement.

\section{Materials and Methods}

School based cross-sectional study was conducted in School going adolescents, from schools around Indira Gandhi Institute of Child Health, Bangalore for 1 year, from December 2012 to November 2013.

Using cluster random sampling method, three schools were included in the study, as the required sample size was met in these three schools. All students in these three schools were included.

Before initiating the study, permission for carrying out the work was obtained from the Principals of the selected high schools. As far as possible, the free time/physical activity periods were used for this study so that the routine classes were unaffected. Prior consent from the teachers and students were obtained.

The students were given a pre-designed structured questionnaire which consisted of questions to be answered by the student, with the help of his/her parents at home. The questionnaire was explained to the students beforehand. It included demographic description, annual income, dietetic history and physical activity.

As some questions like birth weight, required parental help, the questionnaire was given to the students, to be taken home, filled and then brought the next day. Also parents were requested to fill the family history in the questionnaire.

The age was taken from the school register. Age group was rounded off to the nearest whole year. Thus if a subject was 12year 3 months, he/she was included as 12 years and if the subject was 12 year 7 months he/she was included as 13 years.

\section{Measurements}

1. Height: It was measured without any footwear to the nearest of $0.1 \mathrm{~cm}$ using a standard calibrated bar. The student stood straight with heels, buttocks, back touching the vertical limb of the instrument and stretching upward to the fullest extent with arms hanging on the sides.

The head was aligned so that the lower rim of the orbit and the auditory canal were in the horizontal plane (Frankfurt place). Mild upward pressure was exerted on the mastoid region bilaterally.

2. Weight: It was measured without any footwear with minimal clothing (school uniforms) to the nearest of 0.1 $\mathrm{kg}$ using a standard portable weighing machine and the scale was zeroed before each session and weight was recorded in kilograms.

The BMI was then calculated. Children with BMI $>95^{\text {th }}$ centile for age and gender as per NCHS charts were classified as obese [6].

Statistical Methods: Descriptive statistical analysis has been carried out in the present study. Results on continuous measurements are presented on Mean \pm SD (Min-Max) and results on categorical measurements are presented in Number (\%). Significance is assessed at $5 \%$ level of significance. Student $t$ test (two tailed, independent) has been used to find the significance of study parameters on continuous scale between two groups (Male and Female).

Chi-square test $/ 2 \times 2,2 \times 4$ Fisher exact test has been used to find the significance of incidence of obesity in relation to study characteristics. Odds ratio has been computed to find the strength of relationship between the incidence of obesity and study characteristics. 95\% confidence interval has been used in the present study.

\section{Results}

An observational study consisting of 748 children is undertaken to study the prevalence of obesity. The maximum number of adolescents in the present study belonged to the 14 years age group. $38.2 \%$ adolescents belong to 14 years age group. The graph depicts a normal distribution of subjects. Males constituted $62.2 \%$ of the subjects studied. And females constituted $37.8 \%$ of the study group.

The majority of the adolescents studied had a birth weight of 2.5 to $3.5 \mathrm{~kg}$. There was family history of hypertension in $19.4 \%$, diabetes mellitus in $8.7 \%$, obesity in $9.9 \%$ and cardiovascular diseases in $1.1 \%$ of the total adolescents studied. More number of adolescents had a mixed diet pattern. (Table 1) 
Table-1: Base line characteristics

\begin{tabular}{|c|c|c|}
\hline Characters & Number & $\%$ \\
\hline \multicolumn{3}{|c|}{ Age in years } \\
\hline 12 years & 19 & 2.5 \\
\hline 13 years & 140 & 18.7 \\
\hline 14 years & 286 & 38.2 \\
\hline 15 years & 204 & 27.3 \\
\hline 16 years & 91 & 12.2 \\
\hline 17 years & 8 & 1.1 \\
\hline \multicolumn{3}{|c|}{ Gender } \\
\hline Male & 465 & 62.2 \\
\hline Female & 283 & 37.8 \\
\hline \multicolumn{3}{|c|}{ Birth weight } \\
\hline $1.50-2.50$ & 132 & 17.6 \\
\hline $2.50-3.50$ & 535 & 71.5 \\
\hline$>3.50$ & 75 & 10.0 \\
\hline Unknown & 6 & 0.8 \\
\hline \multicolumn{3}{|c|}{ Diet pattern } \\
\hline Vegetarian & 230 & 30.7 \\
\hline Mixed & 518 & 69.3 \\
\hline \multicolumn{3}{|c|}{ Family history } \\
\hline Hypertension & 145 & 19.4 \\
\hline Diabetes mellitus & 65 & 8.7 \\
\hline Obesity & 74 & 9.9 \\
\hline Cardiovascular disease & 8 & 1.1 \\
\hline
\end{tabular}

Table-2: Prevalence of Obesity

\begin{tabular}{|c|c|c|}
\hline Number of children & No. of children with obesity & \% \\
\hline 748 & 44 & 5.9 \\
\hline
\end{tabular}

The prevalence of obesity in adolescents was found to be $5.9 \%$ in the present study were found to be obese (Table 2 ). Among the factors influencing the prevalence of obesity, highest prevalence of obesity was in the 15 year age group. When the age specific prevalence of obesity in 15 year olds was compared to the overall prevalence of $5.9 \%$, a p value of 0.039 was obtained which was moderately significant. Males were more obese when compared to females in the present study. Gender specific prevalence of obesity was not significant when compared to the overall prevalence. (Table 3)The Birth weight specific prevalence of obesity was compared to the overall prevalence in the present study. More obese adolescents had a birth weight $>3.5 \mathrm{~kg}$ with a p value of 0.069 .

Among obese adolescents, $79.5 \%$ had mixed diet pattern and only $20.5 \%$ had vegetarian diet. Incidence of obesity is positively related to the mixed diet pattern with $\mathrm{p}=0.127$. Among adolescents with family history of Obesity, $22.9 \%$ were obese. However, among adolescents without family history of Obesity, only $4.1 \%$ were obese. Hence, family history of Obesity is significantly associated with obesity. Majority of obese adolescents belonged to upper middle class socioeconomic status with a p value of 0.028 which was moderately significant. (Table 4) 
Table 3: Demographic factors influencing the prevalence of obesity

\begin{tabular}{|c|c|c|c|c|}
\hline & Number of children & $\begin{array}{l}\text { No. of children } \\
\text { with obesity }\end{array}$ & $\%$ & Significance \\
\hline \multicolumn{5}{|c|}{ Age in years } \\
\hline 12 years & 19 & 0 & 0 & - \\
\hline 13 years & 140 & 10 & 7.1 & 0.546 \\
\hline 14 years & 286 & 10 & 3.5 & $0.085+$ \\
\hline 15 years & 204 & 19 & 9.3 & $0.039^{*}$ \\
\hline 16 years & 91 & 5 & 5.5 & 0.871 \\
\hline 17 years & 8 & 0 & 0 & - \\
\hline Total & 748 & 44 & 5.9 & - \\
\hline \multicolumn{5}{|c|}{ Gender } \\
\hline Male & 465 & 32 & 6.9 & 0.361 \\
\hline Female & 283 & 12 & 4.2 & 0.225 \\
\hline Total & 748 & 44 & 5.9 & - \\
\hline \multicolumn{5}{|c|}{ Family history } \\
\hline Hypertension & 145 & 16 & 36.4 & $0.003 * *$ \\
\hline Diabetes mellitus & 64 & 7 & 15.9 & $0.090+$ \\
\hline Obesity & 76 & 17 & 38.6 & $<0.001^{* *}$ \\
\hline Cardiovascular disease & 8 & 1 & 2.3 & 0.386 \\
\hline
\end{tabular}

Table 4: Factors influencing obesity

\begin{tabular}{|c|c|c|c|c|}
\hline & $\begin{array}{c}\text { Number of } \\
\text { children }\end{array}$ & $\begin{array}{l}\text { No. of children with } \\
\text { obesity }\end{array}$ & $\%$ & Significance \\
\hline \multicolumn{5}{|c|}{ Birth weight } \\
\hline $1.50-2.50$ & 132 & 8 & 6.1 & 0.922 \\
\hline $2.50-3.50$ & 535 & 28 & 5.2 & 0.492 \\
\hline$>3.50$ & 75 & 8 & 10.7 & $0.069+$ \\
\hline Total & 748 & 44 & 5.9 & - \\
\hline \multicolumn{5}{|c|}{ Diet pattern } \\
\hline Vegetarian & 330 & $221(31.4 \%)$ & 9 & \\
\hline Mixed & 518 & $483(68.6 \%)$ & 35 & $0.013 *$ \\
\hline \multicolumn{5}{|c|}{ Socio-economic status } \\
\hline Upper class & 14 & 0 & 0 & - \\
\hline $\begin{array}{l}\text { Upper middle } \\
\text { class }\end{array}$ & 197 & 19 & 9.6 & $0.028^{*}$ \\
\hline $\begin{array}{l}\text { lower middle } \\
\text { class }\end{array}$ & 363 & 16 & 4.4 & 0.223 \\
\hline upper lower & 175 & 9 & 5.1 & 0.653 \\
\hline Lower & 0 & 0 & 0 & - \\
\hline Total & 748 & 44 & 5.9 & - \\
\hline
\end{tabular}

\section{Discussion}

The present study showed that the prevalence of obesity is $4.2 \%$ in girls as compared to $6.9 \%$ in boys, with overall prevalence of $5.9 \%$. Boys were found to be more obese as compared to girls, in the present study. The higher prevalence of obesity in boys could be possibly due to larger number of boys in the present study (62.2\% boys as compared to $37.8 \%$ girls). In a study from Delhi school, it was found that boys were more obese as compared to girls (8.3\% vs. 5.5\%). [7] However, in a Brazilian study, it was found girls to be more obese than boys (8.7\% vs. 6.4\%) [8]. A study involving adolescent children (between 10-15 years of 
age) of the affluent families of Amritsar district of Punjab, the prevalence of overweight and obesity in 640 was reported. Among overweight adolescents in their study, 50.4\% $(\mathrm{n}=323)$ were boys and $49.6 \% \quad(\mathrm{n}=317)$ were girls and $4.95 \%(n=16)$ boys and $6.31 \%(n=20)$ girls were obese [9].

The majority of children included in the present study had birth weight of 2.5 to $3.5 \mathrm{~kg}$. The highest prevalence of obesity was found in children in the birth weight group of $>3.5 \mathrm{~kg}$. This finding is in contrast to the Barker's Hypothesis. However, in a study from Athens it was found that excess birth weight was one of the significant predictors of obesity in Greek children [10].

The majority of children in the present study had a mixed diet and incidence of obesity is positively related to mixed diet pattern.

Majority of obese children in our study belonged to upper socio economic status. A Chennai study in 2002, involving six schools, two from each high, middle and lower income groups reported the prevalence of overweight (including obese) adolescents ranged from $22 \%$ in better of school to $4.5 \%$ in lower income group schools [11].

In a study of obese adolescents in Karachi Pakistan, out of 284 students, $6 \%(n=17)$, were obese. Of all obese children, $70 \%(n=12)$ belonged to the higher socioeconomic status group. Amongst obese children, 65\% ate meat everyday, compared to $33 \%$ of normal kids [12].

There was a statistically significant prevalence of hypertension, obesity and diabetes mellitus in the families of children with obesity. Results from a Brazilian study, show that having parents with high BMI values is a risk factor for obesity in adolescents.

Although family aggregation of obesity certainly has a genetic component, it has also been demonstrated that a child or adolescent is at risk of becoming obese simply by living with other obese persons, independent of the existence or not of biological relationships among them [13].

One of the limitations of the study was there was no objective evidence regarding the prevalence of obesity, hypertension, DM and cardiovascular diseases in the family. Other limitations include, history of recent illnesses which might have resulted in weight loss during the study period was not taken and skin fold thickness was not used to assess prevalence of obesity.

\section{Conclusion}

To conclude, there is a significant higher prevalence of obesity among adolescents of urban Bangalore. Mixed diet and family history of obesity have a strong correlation with the prevalence of obesity in adolescents. Improvement in socio-economic status is a significant risk factor for increase in prevalence of obesity among adolescents. Obese adolescents should be monitored for co-morbid conditions like sleep disturbances in the form of snoring and obstructive sleep apnea.

We recommend, any child with a family history of obesity, diabetes mellitus, hypertension or cardiovascular disease should be monitored for obesity. As obesity is more prevalent in higher socio-economic status families, emphasis should be made on promoting life style changes like decreased physical activity and decreased caloric intake.

Ethical approval: Obtained from Institutional Ethics Committee (Human Studies)

Funding: No funding sources.

Conflict of Interest: The authors declare no conflict of interest

\section{References}

1. Styne DM. Childhood and adolescent obesity. Prevalence and significance. Pediatr Clin North Am. 2001 Aug;48 (4):823-54.

2. Must A, Jacques PF, Dallal GE, Bajema CJ, Dietz WH. Long-term morbidity and mortality of overweight adolescents. A follow-up of the Harvard Growth Study of 1922 to 1935. N Engl J Med. 1992 Nov 5;327(19):1350-5.

3. Hill Jo and Trowbridge FL(Ed). Symposium on the causes and health consequence of obesity in children and adolescents. Pediatrics. 1998; 101: S497-S574.

4. Dietz WH. Overweight in childhood and adolescence. N Engl J Med. 2004 Feb 26;350(9):855-7.

5. Moran R. Evaluation and treatment of childhood obesity. Am Fam Physician. 1999 Feb 15;59(4):861-8, 871-3. 
6. Ogden CL, Flegal KM. Changes in terminology for childhood overweight and obesity. Natl Health Stat Report. 2010 Jun 25;(25):1-5.

7. Kapil U, Singh P, Pathak P, Dwivedi SN, Bhasin S. Prevalence of obesity amongst affluent adolescent school children in delhi. Indian Pediatr. 2002 May;39(5):449-52.

8. Sawaya AL, Dallal G, Solymos G, de Sousa MH, Ventura ML, Roberts SB, Sigulem DM. Obesity and malnutrition in a Shantytown population in the city of São Paulo, Brazil. Obes Res. 1995 Sep;3 Suppl $2: 107 \mathrm{~s}-115 \mathrm{~s}$.

9. Sidhu S, Marwah G, Prabhjot. Prevalence of overweight and obesity among the affluent adolescent school children of Amritsar, Punjab. Coll Antropol. 2005 Jun;29(1):53-5.

10. Priftis KN, Panagiotakos DB, Anthracopoulos MB, Papadimitriou A, Nicolaidou P. Aims, methods and preliminary findings of the Physical Activity, Nutrition and Allergies in Children Examined in Athens (PANACEA) epidemiological study. BMC Public Health. 2007;7:140.

11. Ramachandran A, Snehalatha C, Vinitha R, Thayyil M, Kumar CK, Sheeba L, Joseph S, Vijay V. Prevalence of overweight in urban Indian adolescent school children. Diabetes Res Clin Pract. 2002 Sep;57(3):185-90.

12. Warraich HJ, Javed F, Faraz-Ul-Haq M, Khawaja FB, Saleem S. Prevalence of obesity in school-going children of Karachi. PLoS One. 2009;4(3):e4816. doi: 10.1371/journal.pone.0004816. Epub 2009 Mar 24.

13. Neutzling MB, Taddei JAAC, Gigante DP. Risk factors of obesity among Brazilian adolescents: a casecontrol study. Public Health Nutr [Internet]. 2003;6(08):743-9. Available from: http://www.journals.cambridge.org/abstract S1368980003001009.

\section{How to cite this article?}

Niranjan H S, Nijaguna N, Kamath G. Prevalence of obesity among the school going adolescents in urban Bangalore. Pediatr Rev: Int J Pediatr Res 2015;2(4):107-112.doi:10.17511/ijpr.2015.i04.13 